\title{
Surveying US College and University Dining Services for Potential Collaboration on Diet Change Research 2017-2018
}

\author{
Jacob Peacock* \\ III LABS
}

Humane League Labs Report E013R01

Published February 20, 2019

Executive Summary Collaboration with colleges and universities may be a promising opportunity for collecting data on what foods people buy. This data could support research in animal advocacy and other fields seeking to change diet, including reducing the purchase and consumption of animal products. To help build these collaborations, information about the dining services at 66 campuses in the United States was collected. Using this information, we tried to identify campuses which were likely to have detailed information on the food students buy and be willing to collaborate with researchers. We identified three such campuses and 25 campuses that likely do not meet those criteria. Researchers should consider collaborating with the identified campuses, searching for additional campuses as well as alternative research methods that do not require such detailed information.

\footnotetext{
This research earned the Open Data and Materials badges for open science
practices. All data is available on the Open Science Framework repository at
https://osf.io/zh26w/.
}

*Corresponding author: jpeacock@thehumaneleague.org (iD 0000-0002-4834-8132

This work is licensed under the Creative Commons Attribution 4.0 International License. To view a copy of this license, visit http://creativecommons.org/licenses/by/4.0/ or send a letter to Creative Commons, PO Box 1866, Mountain View, CA 94042, USA. 


\section{Contents}

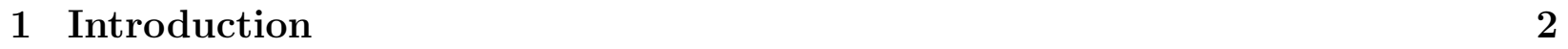

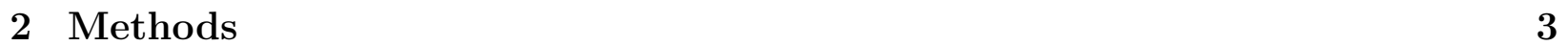

2.1 Survey design . . . . . . . . . . . . . . . . . . . . . . . . 3

2.2 Sample design . . . . . . . . . . . . . . . . . . . . . . . . . 3

2.3 Survey administration . . . . . . . . . . . . . . . . . . . . 4

2.3 .12017 survey . . . . . . . . . . . . . . . . . . . . . . 4

$2.3 .2 \quad 2018$ survey $\ldots \ldots \ldots \ldots$. . . . . . . . . . . . . . . . . . . 4

2.4 Interviews and online research . . . . . . . . . . . . . . . . . . . 5

2.5 Analysis . . . . . . . . . . . . . . . . . . . . 5

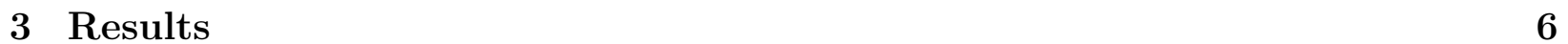

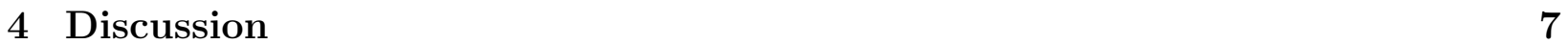

4.1 Campuses likely to have detailed dining data . . . . . . . . . . . . . . . . 7

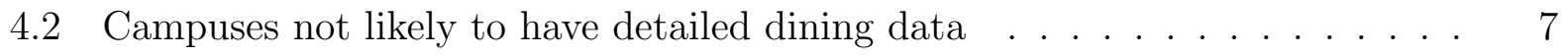

4.3 Suggestions for future surveys . . . . . . . . . . . . . . . . . . . 9

\begin{tabular}{llr}
\hline 5 & Conclusions & 9
\end{tabular}

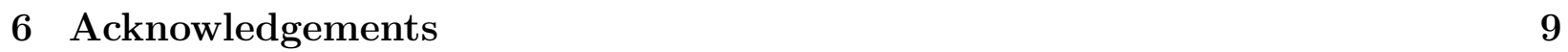

\begin{tabular}{lll}
\hline 7 & References & 10
\end{tabular}

\section{Introduction}

Measuring diet change has often relied on self-reporting, where subjects are asked to describe their diet and their responses are analyzed to determine changes in diet. However, self-reports of diet have been demonstrated to have low correlation with actual diet and high variance in errors, reducing the accuracy and statistical power of research relying on self-reporting. Food purchasing data is a more reliable alternative for measuring diet change and may be available via collaboration with institutions selling food, as we discussed in [1]. College and university dining services may be especially favorable candidates for collaboration as some record highly granular food purchasing data including the food items purchased by each student at each meal [2]. This detailed data with many observations could provide improved statistical power compared to more aggregated food purchasing data like commercially available grocery 
scanner data. Furthermore, many campuses have existing health and environmental goals that may be served by interventions designed to reduce consumption of animal products, making collaboration mutually beneficial.

With the abundance of college and university campuses throughout the United States (US), it seems likely high-quality food purchasing data could be obtained through collaboration. Because information on dining services record keeping is not readily available to the public, Humane League Labs collaborated with The Humane League's campus organizing program, in which students throughout the US are employed to organize animal advocacy on their campuses as campus organizers (COs). Humane League Labs surveyed COs to learn more about dining services on their campuses and the potential qualities of their food purchasing data.

\section{Methods}

\section{$2.1 \quad$ Survey design}

Based on principles of experiment design and experience from previous collaboration, the survey instrument was designed to identify campuses meeting the following candidate criteria:

1. Individual food items are available for purchase via à la carte dining, rather than all-you-can-eat, all-you-care-to-eat, or buffet dining where a single payment provides access to an array of foods.

2. The purchase of a food item is linked directly to the student, for example, via a student identification card used for purchases.

3. The majority of students regularly dine à la carte and use their student identification card to pay.

4. The dining service company is either operated by the campus ("self-operated") or a relatively small company that may afford flexibility and independence to cooperate with research efforts.

\subsection{Sample design}

The Humane League employs COs on an annual basis and at a different set of campuses each year. COs are hired based primarily on their interest in the work of The Humane League and their aptitude as organizers, rather than their attendant campus. That said, campuses with larger student bodies and residential (rather than, for example, commuter) student 
bodies are favored to maximize impact. Since this survey is designed to identify potential campuses for collaboration, this convenience sample is sufficient, although it is not likely a representative sample of campuses in the US. Nonetheless, this design admits the possibility of selection bias.

\subsection{Survey administration}

Surveys were distributed to two cohorts of COs starting work in September 2017 and 2018. The survey for the 2017 cohort was run during the latter half of the school year (March through May of 2018), while the 2018 cohort survey was run through the first month of the school year (August through September 2018). Note that while both surveys were carried out in 2018, the survey respondents were from the 2017 and 2018 cohorts of COs. Thus we refer to the two as the 2017 and 2018 surveys, respectively. Similar survey instruments were used for each survey, with improvements made to the 2018 survey based on the results of the 2017 survey. In total, 82 unique campuses were surveyed, with 18 surveyed in both years. The details of each survey are provided below. All file names and paths refer to the Open Science Framework repository at https://osf.io/zh26w/ where the survey materials, data and computer code for analysis can be found.

\subsubsection{7 survey}

The survey was self-administered using Google Forms and distributed to COs representing 45 campuses (listed in data/2017-Campuses.csv). It was released via the instant messaging application Slack on March 12, 2018 (materials/2018-03-12-survey-release.txt). A follow-up reminder was sent to all COs, also via Slack, on May 1 (materials/201805-01-follow-up.txt). On May 23, 2018, the survey was closed to responses and the anonymized results recorded (data/2017-Survey-on-Campus-Dining-Services.csv). For the complete text of the survey, see materials/2017-Survey-1.pdf and materials/2017Survey-2.pdf, Parts 1 and 2, respectively. If the question in Part 1 "Is there à la carte dining on campus?" was answered with "No", the survey ended; otherwise, respondents continued to Part 2.

\subsubsection{8 survey}

The survey was self-administered using Google Forms and distributed to COs representing 55 campuses (listed in data/2018_Campuses.csv). On August 10, 2018, the COs were informed via email of a mandatory video meeting on August 17 to discuss this project and 
the survey (materials/2018-08-10-notification-of-meeting.pdf). During that meeting, the author described the project, explained the survey instrument to the COs, and fielded questions. The survey itself was sent via email on August 20, along with a video recording of the August 17 meeting for those COs not in attendance (materials/201808-20-survey-release.pdf). A follow-up reminder was sent via email to non-respondents on September 13 (materials/2018-09-13-follow-up.pdf) and final individual follow-ups to non-respondents sent via the instant messaging application Slack on September 17. On

September 26, 2018, the survey was closed to responses and the anonymized results recorded (data/2018-Survey-on-Campus-Dining-Services.csv). For the complete text of the survey, see materials/2018-Survey-1.pdf and materials/2018-Survey-2.pdf, Parts 1 and 2 , respectively. If the question in Part 1 "Is there à la carte dining on campus?" was answered with "No", the survey ended; otherwise, respondents continued to Part 2.

\subsection{Interviews and online research}

Two unstructured interviews were carried out with campuses of interest with the relevant results reported below. Online research was undertaken to better understand the dining services on some campuses by reviewing their websites, cited herein. Lastly, members of Menus of Change, an organization which works with campus dining services to promote reduced animal product consumption among other goals, were identified from their membership list [3. The Menus of Change University Research Collaborative promotes research to achieve the goals of Menus of Change; thus membership suggests a campus may be interested in research collaboration.

\subsection{Analysis}

Three primary analyses were carried out: comparison of campuses providing responses in both surveys, filtering of responses that met the candidate criteria and scoring of responses for how closely they match the candidate criteria.

The first analysis consisted of identifying campuses providing multiple responses to the survey and then examining the similarity of those responses. The consistency across responses was tabulated for several questions.

The second analysis identified campuses with responses that may meet the candidate criteria and then examined all responses from those campuses. In particular, the responses were filtered to those with à la carte dining used by at least a majority of students; where meals can be purchased with a student identification card and students use that system for 
at least half of meals; where receipts displayed itemized purchasing information and where dining services were not provided by the major dining services companies Aramark or Sodexo. Where respondents did not know the answer to a question, the response was included during the filtering in order to produce a set of campuses that may meet the candidate criteria.

The third analysis attached a numeric value to each response based on how closely the answers to the survey questions came to meeting the candidate criteria. Because the question on the campuses' dining service company was free response, the answers were not standardized and therefore not considered in the score. The scores of responses for each campus were then summed to give a campus score, with higher scores indicating more confidence that the campus is near the candidate criteria. The Python code providing complete details for the cleaning, validation and three analyses of the data is provided in analysis-code/Analysis.ipynb, along with details for executing the code in analysiscode/README. txt.

\section{Results}

The surveys received 27 and 54 responses for response rates of $60 \%$ and $98 \%$ in 2017 and 2018, respectively, and a total of 81 responses. The difference in response rates is likely attributable to the consecutive and individualized follow-ups used in the 2018 survey. The responses correspond to 66 unique campuses, with 15 campuses providing responses in both surveys. (That is, 272017 campuses +542018 campuses -15 duplicated campuses $=66$ unique campuses.)

These pairs of responses often differed, suggesting some combination of changes in campus conditions, effects of differences in survey instrument or administration, and respondent error. For example, the first substantive question of the survey on the presence of à la carte dining on campus received different answers in 5 of 15 cases across the two years. There was no obvious correlation to the year of survey administration, which suggests this result is not attributable to differences in respondent understanding of the survey or its administration. These results suggest the survey instrument as administered had low reliability.

In accordance with the design of the surveys, responses were filtered to find campuses that may meet the candidate criteria. This process identified 12 campuses, 5 of which responded in both the 2017 and 2018 surveys. Of these 5 campuses, 3 met the candidate criteria in just one of the two years of surveys, underscoring concerns about reliability. Because the filtering erred on the side of caution and allowed the inclusion answers of "I don't know", identified campuses had many unknowns in their responses. While overall $13 \%$ of questions received an answer of "I don't know", responses for the campuses identified through filtering 
had $21 \%$ unknowns.

In light of low reliability and high rate of unknowns in responses, a scoring approach was devised that is less sensitive to errors and scores only the available information. The possible scores ranged from -6 to 8 , with the lower extreme indicating a campus not likely meeting the candidate criteria and the upper extreme indicating a campus likely meeting the candidate criteria. Empirically, scores ranged from -6 to 6.75 , with the first quartile at -3 , median 0.375 and third quartile 2.25. A subjective evaluation suggests scores below 2.25 represented campuses far from meeting the candidate criteria and with significant unknowns in the survey responses. 19 campuses fell at or above this threshold, including 10 of the 12 campuses identified in the filtering analysis.

\section{Discussion}

A holistic and qualitative approach was ultimately used to make suggestions for which campuses may have detailed dining data. Where sufficient information was available, a synthesis of the campuses' score, dining services company, supplemental interviews, and online research was used to make a suggestion. Where sufficient information was not available, no suggestion was made. Based on the reliability of the survey, these suggestions should be regarded as tentative and, given the dynamics of dining service contracts, subject to change.

\subsection{Campuses likely to have detailed dining data}

If you are considering building relationships with these campuses, please contact the author so research efforts can be appropriately coordinated.

- The Ohio State University Although the three dining halls have all-you-care-to-eat dining, responses indicate a large fraction of meals may be consumed at à la carte facilities on campus. The campus participates in Menus of Change and further research suggests the dining services are self-operated [4].

- University of Puget Sound Self-operated dining service scoring high on all questions.

- Washington State University Self-operated dining service, scoring relatively well but the fraction of students eating at dining services may be low.

\subsection{Campuses not likely to have detailed dining data}

- Montana State University Although run by an independent dining service, a further interview suggests mostly freshman and sophomores eat at dining services and primarily 
at the all-you-care-to-eat facilities.

- Northeastern University Survey response suggests many third-party vendors on campus, although dining services may be self-operated.

- San Diego State University Although run by an independent non-profit dining service, a further interview suggests students eat primarily at private restaurants and franchises on campus.

- The George Washington University Dining services distributed across "over 90 places on campus and around DC" (quoted from survey response).

- Texas Tech University High scoring and dining services may be self-operated [5], but further research shows many third-party vendors on campus.

- Western Michigan University High scoring, but major dining halls are all-you-care-toeat facilities 6 .

The following campuses were found to have no à la carte options:

- Boise State University Responses to both survey indicate no à la carte options.

- California State University Long Beach

- Emerson College

- Kennesaw State University

- Loyola University Chicago

- Mount Holyoke College

- Northern Illinois University

- Pomona College

- Rutgers University, New Brunswick

- University of California, Santa Barbara

- University of California, Santa Cruz Responses to both survey indicate no à la carte options.

- University of Central Florida

- University of Houston

- University of Maryland College Park

- University of San Diego

- University of St Thomas

- University of West Florida

- Wofford College

- Worcester Polytechnic Institute 


\subsection{Suggestions for future surveys}

The results suggest several changes in methodology for the continuation of this work. First, interviewer-administrated surveys rather than self-administered surveys may be preferred to reduce the rate of unknowns in responses by prompting with follow-up questions and clarifications. Second, online research might be used to obtain or corroborate information on the campuses' dining service company, rather than relying primarily on the respondent's account. Online research could also be used to identify campuses with third-party vendors that would hinder data collection. Third, future surveys should not end after a negative response to the à la carte question in the event that answer is incorrect and so as to provide additional information to evaluate reliability.

\section{Conclusions}

After evaluating 66 campuses, it appears likely that dining services recording granular food purchasing data at the level of individual students and meals is uncommon among US colleges and universities. In light of this, researchers might consider alternative approaches to utilizing campus dining data. For example, outcomes could be measured in terms of aggregate sales or purchasing data and randomization might take place across dining facilities on campus. It may also be worthwhile to explore collaboration with dining service companies rather than individual campus dining services. Dining service companies with existing environmental and animal welfare focuses, like Bon Appétit [7], may be strong candidates. Finally, in building relationships with colleges and universities, a coordinated approach would best serve all involved by ensuring resources are well allocated and dining services are not unduly engaged by multiple researchers. If you are interested in developing relationships with campuses identified in this study, please contact the author so research efforts can be appropriately coordinated.

\section{Acknowledgements}

Thank you to The Humane League staff who made the COs available for surveys and interviews: Stephanie Frankle, Chris Guinn, José Elias, Meghan Smith, and Katie Zarajczyk. Thank you also to Josh Tasoff and Kieran Greig for guidance in formulating the candidate criteria and survey. A special thank you is due to the COs for formulating responses to the survey. We thank the Sentience Institute (https://www.sentienceinstitute.org/) 
for reviewing the availability of the data and materials for the Open Data and Materials Badges.

\section{References}

[1] Jacob Peacock. Measuring Change in Diet for Animal Advocacy. E009R01. Humane League Labs, Nov. 7, 2018. DOI: DOI10.17605/OSF. IO/8ZQC3. URL: https://forum. effectivealtruism . org/posts/Z6QhwL3MDppdrygQB/measuring-change-in-dietfor-animal-advocacy.

[2] Gina Stuessy. Study Proposals from Our First Research Workshop on Effective Animal Advocacy. Oct. 24, 2017. URL: https : //web.archive.org/web/20181116212314/ https : / / animalcharityevaluators . org / blog / study - proposals - from - our first-research-workshop-on-effective-animal-advocacy/ (visited on 11/16/2018).

[3] The Menus of Change University Research Collaborative. Menus of Change University Research Collaborative. 2018. URL: https://web.archive.org/web/20190128233629/ http://www.moccollaborative.org/ (visited on 01/28/2019).

[4] The Ohio State University. Dining Locations. Jan. 16, 2019. URL: https : / / web . archive . org/web/20190116183835/https : / / dining . osu . edu / locations/ (visited on $01 / 16 / 2019)$.

[5] Texas Tech University Hospitality Services. Surrounded by Choices! URL: https : // web.archive.org/web/20190116190320/http://www.depts.ttu.edu/hospitality/ dining.php (visited on 01/16/2019).

[6] Western Michigan University. About Us. URL: https : / / web . archive . org / web / 20190129222654/https://wmich.edu/dining/about (visited on 01/29/2019).

[7] Bon Appétit Management Company. Animal Welfare. URL: https://web .archive . org/web/20181207161059/http : / / www . bamco . com / sourcing/animal -welfare/ (visited on $01 / 29 / 2019$ ). 